\title{
EVALUASI PENGENDALIAN INTERNAL SISTEM INFORMASI AKUNTANSI ATAS SIKLUS PENJUALAN DAN PENERIMAAN KAS (Studi Kasus pada PT. GEOFF MAKSIMAL JAYA)
}

\author{
Alya Tasqiya Khumaira \\ Fakultas Ekonomi dan Bisnis, Universitas Padjadjaran, Indonesia \\ E-mail: alyatasqiya14@gmail.com
}

\begin{abstract}
This study aims to examine and find about implementation of internal control evaluation of Accounting Information Systems (Case Study at PT Geoff Maksimal Jaya. Sales and cash receipts are one of the most important components for a company and are very easy to abuse. The purpose of this study is to evaluate the weaknesses and strengths of the internal control system of the accounting information system on cash receipts for the sales cycle at PT Geoff Maximal Jaya. This research is a qualitative research using an evaluation program by comparing it with internal control based on COSO theory. The results of this study are the internal control of cash receipts over the sales cycle is quite good, but there are still aspects that are not in accordance with COSO theory, namely the merger between the sales function and the credit function.
\end{abstract}

Keywords: Internal Control, Sales and Cash Receipt Cycle, COSO

\section{PENDAHULUAN}

Pada era saat ini, dunia bisnis industri kreatif berkembang sangat pesat disertai perkembangan teknologi. Fenomena bisnis industry kreatif di Indonesia semakin di gandrungi dan menjadi tren generasi millennial yang mengakibatkan persaigan yang semakin ketat pula. PT Geoff Maksimal jaya yang merupakan salah satu perusahaan industri kreatif yang berasal dari Kota Bandung yang sudah bergerak kurang lebih 8 tahun. Perusahaan melakukan aktivitas penjualan online dan penjualan offline sedangkan dalam penerimaan kas dilakukan dengan berbagai cara yaitu transfer ke rekening yang telah perusahaan sediakan, melalui mesin EDC, Tunai, Tunai secara berangsur-angsur serta melalui pihak ketiga yaitu marketplace yang pada akhirnya ditransfekan kembali ke rekening yang telah disediakan perusahaan dengan tenggang waktu sesuai kebijakan dari masing masing marketplace.

Aktivitas chanel penjualan dan penerimaan kas di PT Geoff Maksimal jaya yang bervariasi, maka PT Geoff Maksimal jaya harus mempunyai pengendalian internal dan sistem informasi akuntansi atas siklus penjualan dan penerimaan kas yang baik. Pengendalian internal adalah suatu tindakan untuk memastikan bahwa aktivitas perusahaan dilakukan seusai dengan kebijakan dan peraturan manajemen (Karmana, 2019).Tanpa adanya pengendalian internal yang baik perusahaan dapat mengalami kerugian yang besar dengan adanya kecurangan yang tidak terdeteksi ataupun karena sumber daya yang tidak optimal (Sarapi et al., 2019).

Sistem informasi akutansi siklus penjualan dan penerimaan kas merupakan salah satu subsistem informasi akuntasi yang menjelasakan prosedur dalam melaksanakan aktivitas penjualan dan penerimaan kas sehingga dapat menghindari tindakan kecurangan yang dilakukan pegawai baik disengaja ataupun tidak (Kalumata et al., 2017). Dengan adanya pengendalian internal sistem informasi akuntansi atas siklus penjualan dan penerimaan kas yang baik akan meminimalisir resiko dan membuat aktivitas perusahaan telah berjalan dengan efesien dan efektif dan mendorong tujuan perusahaan tercapai. Berdasarkan uraian diatas penelitian ini bertujuan mengevaluasi pengendalian internal sistem informasi akuntansi atas siklus penjualan dan penerimaan kas untuk mengetahui kelebihan dan kekurangan pengendalian internal yang sudah berjalan di PT Geoff Maksimal Jaya dengan cara membandingkan dengan teori yang ada. 


\section{KAJIAN PUSTAKA}

\section{Sistem informasi Akuntansi}

Sistem informasi akuntansi adalah suatu sistem yang mengumpulkan, mencatat, menyimpan, dan mengolah data untuk menghasilkan informasi bagi pengambil keputusan. Sistem informasi akuntansi adalah suatu sistem yang mengumpulkan, mencatat, menyimpan, dan mengolah data untuk menghasilkan informasi bagi pengambil keputusan(Romney \& Steinbart, 2013).

\section{Komponen Sistem Informasi Akuntansi}

Terdapat enam komponen dalam sistem informasi akuntansi. Komponen - komponen tersebut adalah people, Procedures and Instructions, data, software, information technolgy infrastructure, dan internal control and security measures (Romney \& Steinbart, 2013).

\section{Tujuan sistem informasi akuntansi}

Tujuan dari sistem informasi akuntansi adalah meningkatkan kualitas dan mengurangi biaya produk dan jasa, meningkatkan efisiensi, berbgi pengetahuan, meningkatkan efisiensi dan efektivitas rantai suplai, memperbaiki struktur pengendalian internal dan meningkatkan pengambilan keputusan(Romney \& Steinbart, 2013).

\section{Pengendalian internal}

Menurut (COSO, 2013) mendefinisikan pengendalian internal adalah "Internal control is a process, affected by an entity's board of directors, management, and other personnel, designed to provide reasonable assurance regarding the achievement of objectives relating to operations, reporting, and compliance". Pengendalian internal adalah konsep dinamis yang berjalan di dalam organisasi yang merupakan kebalikan dari serangkaian prosedur dasar (Zamzami et al., 2013). Dapat disimpulkan bahwa pengendalian internal adalah prosedur yang dibuat untuk melindungi aset perusahaan yang dijalankan oleh seluruh anggota organisasi sesuai dengan kebijakan yang telah ditetapkan demi mencapai efektivitas dan efisiensi.

\section{Komponen pengendalian internal}

Komponen pengendalian internal adalah Control environment, Risk assessment, Control Activities, Informtion and Communication, am Monitoring Activities (COSO, 2013).

\section{Tujuan Pengendalian internal}

Tujuan utama perusahaan membuat sistem pengedalian internal adalah sebagai berikut (Sujarweni, 2015) adalah menjaga kekayaan perusahaan, menjaga keakuratan laporan keuangan perusahaan, menjaga kelancaran operasi perusahaan, menjaga kedisiplinan dipatuhinya kebijakan management, dan agar semua lapisn yang ada di perusahaan tunduk pada hukum dan aturan yang sudah ditetapkan di perusahaan.

\section{Sistem informasi Akuntasi Penjualan}

Sistem informasi penjualan adalah suatu sistem informasi yang mengorganisasikan serangkian prosedur dan metode yang dirancang untuk menghasilkan, menyebarkan dan memperoleh informasi guna mendukung pengambilan mengenai penjualan(Daud \& windana, 2014).

\section{Sistem informasi akuntansi penerimaan kas}

Sistem akuntansi penerimaan kasialah berasal dari hasil kegiatan normal melalui penjualan tunai baik untuk perusahaan dagang maupun perusahaan jasa, ataupun sebagai hasil penagihan piutang dari perlanggan dalam hal penjualan kredit(Hery, 2016).

\section{METODE PENELITIAN}

jenis penelitian yang digunakan oleh penuulis yaitu peneletian kualitatif yaitu penelitian yang mengevaluasi secara menyeluruh terhadap sistem pengendalian internal atas sikuls penjualan dan penerimaan kas yang diterapkan di PT Geoff Maksimal Jaya dan membandingkan dengan teori yang COSO. Menurut teori penelitian kualitatif, data yang dikumpulkan berupa data primer dan data sekunder. Data primer diperoleh diperoleh dengan cara wawancara kepada Chief Financial Officer dan kuisoner berupa jawaban ya dan tidak, kuesioner yang digunakan menurut COSO Framework 2013. Data sekunder adalah 
data yang tidak langsung diberikan kepada pengumpul data. Data sekunder diperoleh berupa invoice penjualan, bukti penjualan, sistem informasi akuntansi penjualan dan penerimaan kas yang berjalan di perusahaan.

\section{HASIL DAN PEMBAHASAN \\ Hasil}

Unsur unsur pengendalian internal sistem informasi akuntansi atas siklus penjualan dan penerimaan kas yang menjadi dasar analisis dan pembahasan PT Geoff Maksimal Jaya, adalah:

\section{Lingkungan Pengendalian}

Dalam lingkungan pengendalian integritas dan nilai etis PT Geoff Maksimal jaya sangat concern dengan budaya dan etika karyawan dengan cara menerapkan prinsip dasar dalam etika profesi seperti tanggung jawab, keadilan, prinsip kompetensi, prinsip perilaku profesional dan prinsip kerahasiaan, dengan diterapkannya prisip dasar dalam etik profesi membuat pegawai memiliki tanggung jawab dalam melaksanakan tugasnya namun perusahaan ini belum mengadakan pelatihan kode etik. Menurut Idhofi dkk sebelum karyawan diterima menjadi pegawai resmi karwayan diwajibkan untuk mengikuti pelatihan (Idhofi et al., 2018) . Filosofi manajemen dan gaya operasi perusahaan dengan cara perusahaan selalu memastikan pelayanan yang baik, ramah dan produk yang memuaskan setiap pelanggan guna menciptakan proses belanja yang berkepanjangan. Namun didalam perusahaan ini masih dijumpai perangkapan jabatan sedangkan struktur organisasi yang baik adalah bawahan hanya mengenal satu atasan sebagai pemberi wewenang dan berhubungan secara langsung (Kalumata et al., 2017). Akan tetapi PT Geoff Maksimal jaya memiliki pegawai yang mempunyai kompetensi di masing masing divisi yang sangat berpengaruh terhadap aktivitas perusahaan.terutama untuk mengeluarkan kebijakan dan praktik dilapangannya.

\section{Penilaian Risiko}

PT Geoff Maksimal Jaya berusaha meminimalkan resiko dengan baik dengan menggunakan software Accountable untuk mengantisipasi potensi kecurangan pegawai seperti penjualan fiktif yang dilakukan pegawai bagian gudang yang memanfaatkan selisih persediaan barang antara fisik dan sistem sedangkan menurut Fengky pencocokan fisik barang atau kas harus ada bukti tanda tangan atas setiap transaksi yang terjadi(Fengky et al., 2019).

\section{Aktivitas Pengendalian}

Utnuk mencegah fraud pegawainya, PT Geoff Maksimal Jaya berusaha untuk memisakan fungsi accounting dan penjualan. Namun, dikarenakan ruang lingkup perusahaan masih terbatas masih ada perangkapan jabatan seperti terjadi di toko, pegawai toko melakukan aktivitas penjualan dan penerimaan kas sedangkan menurut idhofi dkk hanya karyawan tertentu yang secara khusus untuk melakukan penerimaan kas (Idhofi et al., 2018). Akan tetapi, untuk karyawan yang merangkap jabatan ada pengendalian terhadap otorisasi transaksi dan kegiatannya yang bertujuan untuk menekan fraud.

\section{Informasi dan Komunikasi}

Dalam pencatatan penerimaan kas baik dari penjualan tunai, penjualan kredit sudah dilakukan secara komputerisasi yang dapat di akses oleh bagian yang membutuhkan yang membuat informasi dapat terpenuhi oleh management dan untuk penagihan dan penerimaan kas sudah berdasarkan daftar piutang yang tercantum di dalam sistem. Sedangkan jika terjadi kendala dalam operasional PT Geoff Maksimal jaya sudah melaksanakan meeting Improvement secara berkala yang bertujuan untuk mengatasi masalah dengan cepat.

\section{Monitoring / Pemantauan}

Pengawasaan yang dilakukan PT Geoff Maksimal jaya berjalan dengan cukup baik karena dilakukan secara berkala oleh manajemen dan pemilik. Namun dikarenakan kecenderungan pemilik memberikan kepercayaan penuh terhadap pimpinan dari divisi akan dapat memicu kecurangan yang tidak terindentifikasi khususnya terhadap karyawan yang sudah bekerja dalam periode waktu lama. Dengan adanya pemeriksaan dadakan akan mendorong karyawan melaksanakan tugasnya sesuai dengan aturan yang ditetapkan (Modim et al., 2018). Untuk persediaan barang yang ada di gudang dilakukan pemantauan 
dengan CCTV dan satpam, sedangkan utuk kas sendiri dilakukan pembatasan untuk memasuki area persediaan dan uang kas.

\section{PEMBAHASAN}

\section{Lingkungan Pengendalian}

Berdasarkan Hasil dari penelitian yang dilakukan di lingkungan pengendalian di PT Geoff Maksimal Jaya telah berjalan dengan baik berdasarkan dengan Terori Coso walaupun masih ada kekurangan yaitu adanya perangkapan fungsi penagihan dengan fungsi jabatan akan tetapi kekurangan tersebut dapat ditutup dengan PT Geoff Maksimal Jaya menciptakan lingkungan kerja yang menjunjung tinggi prisip dasar profesi dan memiliki kompetensi di bidangnya masing masing walaupun tidak adanya pelatihan yang dilakukan PT Geoff Maksimal Jaya.

\section{Penilaian Risiko}

Berdasarkan hasil dari peneletian yang dilakukan di penilaian Resiko di PT Geoff Maksimal jaya dapat dikatakan berjalan baik sesuai dengan teori COSO. Dilihat dari adanya sistem yang mencegah kecurangan dari para pegawai dan setiap transaksi baik dalam siklus penjualan dan penerimaan kas terdapat bukti tanda tangan atas transaksi yang terjadi, walaupun masih terjadi ketidakcocokan antra fungsi penagihan dan pernerimaan kas.

\section{Aktivitas Pengendalian}

Dalam aktivitas pengendalian yang dilakukan PT Geoff Maksimal jaya berdasarkan teori COSO dan dapat dikatakan baik walaupun masih dijumpai perangkapan fungsi dikarenakan ruang lingkup perusahaan yang kecil.

\section{Informasi dan Komunikasi}

Dengan adanya sistem yang terkomputerisasi dan adanya meeting secara berkala maka dalam informasi dan komunikasi berdasarkan Teori Coso sudah berjalan dengan baik.

\section{Monitoring / Pemantauan}

Berdasarkan Hasil penelitian yang dilakukan di PT Geoff Maksimal Jaya untuk monitoring / pemantauan sudah sesuai dengan Teori Coso dengan adanya monitoring melalui CCTV yang terpasang disetiap sudut ruangan dan untuk aktivitas di sistem komputer dilakukan pengecekan secara berkala oleh pimpiman setiap divisi. Untuk kekurangan dalam monitoring yang dilakukan oleh PT Geoff Maksimal Jaya adalah tidak adanya pemantauan secara dadakan terhadap pimpinan setiap divisi dikarenakan tingkat kepercayaan yang diberikan oleh pimpinan perusahaan.

\section{KESIMPULAN}

Berdasarkan hasil penelitian dan evaluasi yang dilakukan pengendalian internal terkait dengan siklus penjualan dan penerimaan PT Geoff Maksimal jaya masih terdapat kelemahan jika dibandingkan dengan teori COSO. Kelemahan sebangai berikut :

1. Pada PT Geoff Maksimal Jaya terdapat perangkapan fungsi yaitu pada bagian penagihan dimana posisi tersebut melakukan penjualan akan tetapi juga menerima uang dari pelanggan, hal ini dapat menimbulkan resiko kecurangan pada karyawan.

2. Bagian kasir yang menerima uang akan menyetorkan uang hasil penjualan disetorkan ke bank dan bukti setornya diberikan kepada bagian keuangan, akan tetapi sering terjadi selisih setor dengan data yang dibuat, hal ini mengakibatkan kerugian perusahaan.

3. Perusahaan tidak melakukan tinjauan auditor untuk memverifikasi atas otorisasi yang memadai.

\section{SARAN}

\section{Saran Praktis}

1. Melakukan pemisahan tugas pada bagian komersil dan menambah fungsi penerimaan kas yang dilakukan oleh bagian keuangan dimana penerimaan kas hanya dilakukan oleh bagian keuangan dan tidak boleh dilakukan oleh bagian penjualan agar terhindar dari terjadinya resiko kecurangan. 
2. Melakukan evaluasi berkala kinerja karyawan dan sistem informasi akuntansi atas siklus penjualan dan penerimaan kas untuk memastikan dapat meminimalisir kesalahan atau kecurangan di masa depan

3. Melakukan audit secara berkala untuk memverifikasi atas otorisasi yang bertujuan membuat semua berjalan dengan prosedur perusahaan.

\section{Saran Teroritis}

1. Bagi penelitian selanjutnya diharapkan untuk dapat memperbanyak koresponden. Sehingga mendapatkan data yang lebih baik untuk diolah.

2. Disarankan penelitian selanjutnya untuk membandingkan lebih dari satu teori untuk mengevalusi pengendalian internal sehingga hasil yang diperoleh mendapatkan pengendalian internal yang sangat baik.

\section{REFERENSI}

COSO. (2013). Committee of Sponsoring Organizations of the Treadway Commission (COSO) Internal Control - Integrated Framework Executive Summary. COSO, May.

Daud, R., \& windana, V. (2014). PENGEMBANGAN SISTEM INFORMASI AKUNTANSI PENJUALAN DAN PENERIMAAN KAS BERBASIS KOMPUTER PADA PERUSAHAAN KECIL (STUDI KASUS PADA PT. TRUST TECHNOLOGY). Jurnal Manajemen Dan Bisnis Sriwijaya, 12(1). https://doi.org/10.29259/jmbs.v12i1.3137

Fengky, H., Sabijono, H., \& Kalalo, M. (2019). EVALUASI PENERAPAN SISTEM PENGENDALIAN INTERNAL PENERIMAAN KAS PADA HOTEL YUTA MANADO. Jurnal EMBA: Jurnal Riset Ekonomi, Manajemen, Bisnis Dan Akuntansi, 7(1). https://doi.org/10.35794/emba.v7i1.23218

Hery. (2016). Akuntansi dasar 1 dan 2 Edisi Nasional Best Seller. In Fundamental Management Journal.

Idhofi, V. R., Sudarno, S., \& S., A. B. (2018). Evaluasi Sistem Pengendalian Internal Penerimaan Kas pada Apotek Kimia Farma 307 Banyuwangi. E-Journal Ekonomi Bisnis Dan Akuntansi, 5(1). https://doi.org/10.19184/ejeba.v5i1.7741

Kalumata, N., Nangoi, G. B., \& Lambey, R. (2017). EVALUASI PENGENDALIAN INTERNAL SISTEM INFORMASI AKUNTANSI PENJUALAN DAN PENERIMAAN KAS PADA PT. HASJRAT ABADI CABANG MALALAYANG MANADO. GOING CONCERN： JURNAL RISET AKUNTANSI, 12(2). https://doi.org/10.32400/gc.12.2.18650.2017

Karmana, D. (2019). PERAN AUDIT INTERNAL TERHADAP PENGENDALIAN INTERN PENERIMAAN KAS PADA PT INTI (PERSERO) BANDUNG. Ekonam: Jurnal Ekonomi, Akuntansi \& Manajemen, l(1). https://doi.org/10.37577/ekonam.v1i1.103

Modim, A. R., Tinangon, J. J., \& Pangerapan, S. (2018). EVALUASI PENGENDALIAN INTERN SISTEM INFORMASI AKUNTANSI PENERIMAAN KAS ATAS PENJUALAN JASA KAMAR PADA BIG FISH HOTEL. GOING CONCERN: JURNAL RISET AKUNTANSI, 14(1). https://doi.org/10.32400/gc.13.04.21881.2018

Romney, M., \& Steinbart, P. J. (2013). Sistem Informasi Akuntansi (Accounting Information System) Edisi 13. In Salemba Empat.

Sarapi, D. E. R., Manoppo, W. S., \& Keles, D. (2019). Evaluasi Pengendalian Internal Sistem Informasi Akuntansi Penerimaan Kas Pada PT Bank BRI Cabang Tahuna. JURNAL ADMINISTRASI BISNIS, 8(1). https://doi.org/10.35797/jab.8.1.2019.23495.15-20

Sujarweni, V. W. (2015). Komponen utama sistem informasi. In Sistem Akuntansi.

Zamzami, F., Faiz, I. A., \& Mukhlis. (2013). Audit Internal Konsep dan Praktik. In Juli 2015. 